\title{
OS ANIMAIS DE ESTIMAÇÃO E A DISSOLUÇÃO DA RELAÇÃO AFETIVA DE SEUS DONOS: A POSSIBILIDADE DE APLICAÇÃO DO INSTITUTO DA GUARDA COMPARTILHADA OU A CONSTRUÇÃO DO CONCEITO DE CUIDADO COMPARTILHADO? ${ }^{1}$
}

PETS AND THE DISSOLUTION OF THE AFFECTIVE RELATIONSHIP OF ITS OWNERS: THE POSSIBILITY OF APPLICATION OF THE SHARED GUARD INSTITUTE OR THE CONSTRUCTION OF THE SHARED CARE CONCEPT?

Larissa de Andrade SERRA ${ }^{2}$

ISSUE DOI: $10.21207 / 2675-0104.2018 .750$

\begin{abstract}
RESUMO
O presente artigo tem o escopo de apresentar uma nova realidade do Direito de Família que se refere à disputa da guarda de animais de estimação em sede de divórcio ou dissolução de união estável. Tratase de estudo inovador, de ampla relevância social na ordem jurídica contemporânea, haja vista o aumento no número de animais de estimação no Brasil, em especial cães e gatos, e a inexistência de legislação específica que regulamente o tema. O artigo se desenvolverá a partir de uma análise história da humanidade desde a Revolução Industrial até o mundo moderno, e as mudanças no âmbito familiar nesse ínterim. Em seguida, será analisado o ativismo judicial, em tamanha evidência nos últimos
\end{abstract}

\footnotetext{
${ }^{1} \mathrm{O}$ presente artigo sintetiza a monografia de conclusão da pesquisa, realizada para o Programa Interno de Bolsas de Iniciação Científica (PIBIC 2017-2018) da Faculdade de Direito de Franca (FDF), Franca/SP.

${ }^{2}$ Discente da Faculdade de Direito de Franca (FDF), Franca/SP. Bolsista do Programa Interno de Bolsas de Iniciação Científica (PIBIC 2017-2018).
} 
tempos no Brasil, e seus aspectos para os casos em tela. Por demais, o estudo pormenorizado do status jurídico dispensado aos animais, colocando-se enfoque aos de estimação, e o problema da disputa da guarda destes animais em sede de dissolução da vida conjugal, para que então possa ser analisada a necessidade ou não da elaboração de legislação específica para esses casos.

Palavras-chave: Animais de estimação. Direito de família. Dissolução conjugal. Guarda compartilhada.

\begin{abstract}
The present research has the scope to present a new reality of the Family Law that refers to the dispute of the guarding of pets in divorce or dissolution of stable union. It is an innovative study, of broad social relevance in the contemporary legal order, due to the increase in the number of pets in Brazil, especially dogs and cats, and the lack of specific legislation that regulates the theme. The research will develop from a history analysis of humanity from the Industrial Revolution to the modern world, and changes in the family environment in the meantime. Next, judicial activism will be analyzed, in the light of such evidence in recent times in Brazil, and its aspects for the cases on the screen. Moreover, the detailed study of the legal status given to animals, focusing on pet, and the problem of the dispute over the custody of these animals in the dissolution of conjugal life, so that it can be analyzed the necessity or not of the elaboration specific legislation for such cases.
\end{abstract}

Keywords: Pets. Family right. Conjugal dissolution. Shared guard.

A relação entre os seres humanos e os animais existe desde os tempos mais remotos, quando então ocorria a domesticação dos mesmos para seu uso, por exemplo, no auxílio das atividades agrícolas, na locomoção, na caça e na guarda da propriedade privada, além de servirem também como fonte de alimentação.

Com o passar das épocas e desenvolvimento da sociedade operou-se uma mudança no paradigma social e antropológico até então exposto para descobrir-se quão afetuosos os animais poderiam ser. Assim, a presença desses nos lares passou a não se restringir apenas às funções ora mencionadas, tornando-se cada vez mais frequente a sua existência para os fins de afeto e convivência.

Diante dessa alteração de paradigma, novas questões e problemas surgiram, como, por exemplo, o direito à convivência e a responsabilidade pelo cuidado com os animais de estimação após o rompimento da relação afetiva de seus donos.

Acerca de tal tema, o Poder Judiciário vem sendo cada vez mais instado a se manifestar e não possui, como em outros temas, definições jurídicas sedimentadas para se afiançar e exercer seu importante papel de pacificação social.

Dessa forma, é essencial que se debruce sobre o tema a fim de formular elementos de resposta ou ao menos novas premissas que possam 
fundamentar as decisões judiciais sob o novo enfoque exigido pelos jurisdicionados.

Consoante a isso, a liquidez que marca as relações humanas atualmente, não raro, não se limita apenas ao meio conjugal, mas reflete em todo o contexto familiar, de maneira que os outros vínculos afetivos criados, sejam entre pais e filhos ou com os animais de estimação, não podem ser afetados pelo rompimento do casal.

$\mathrm{Na}$ presente pesquisa, busca-se analisar a eficácia do instituto da guarda compartilhada comumente aplicada pelo Judiciário aos animais de estimação quando da disputa da custódia destes em face de dissolução do vínculo amoroso de seus donos, sobretudo, considerando o enfoque do afeto existente na contemporaneidade.

Para tanto, parte-se de uma abordagem histórica do corpo social a partir da Revolução Industrial e as diversas mutações ocorridas no contexto familiar, principalmente a partir da inserção da mulher do mercado de trabalho, de maneira que novas modalidades familiares foram e continuam sendo inseridas na sociedade e entre elas a denominada família multiespécie, que inclui em seu seio os animais de estimação.

Tomando-se como norte o método indutivo-dedutivo, a presente pesquisa objetiva também analisar o atual status jurídico dispensado aos animais, que são considerados res pelo Código Civil vigente, e demandas jurídicas hodiernas que têm em vista matérias extrapatrimoniais em relação aos animais.

Ademais, mediante ao método comparativo, será realizada uma averiguação das disposições jurisprudenciais acerca da matéria, vislumbrando-se se a aplicação do instituto da guarda compartilhada aos animais de companhia, realmente atende aos objetivos do jurisdicionado após a dissolução conjugal.

Deste modo, a presente pesquisa visa a apresentação de um tratamento jurídico mais adequado aos animais, na medida em que permitiria a elaboração de legislação específica para os casos de disputa de animais de estimação demandados atualmente no Judiciário.

Não se olvida, porém, que independentemente da elaboração de legislação específica ou a aplicação do instituto da guarda compartilhada, o que se visa é o bem-estar animal além do fato de sustentar o vínculo afetivo construído entre o animal e seus donos. 
Nas sociedades conservadoras, ou pré-modernas, para merecer aceitação social e reconhecimento jurídico, os vínculos afetivos necessitavam da "aprovação" do matrimônio. O núcleo familiar era hierarquizado e patriarcal, sendo a figura paterna a provedora pelo sustento familiar, em detrimento da materna, responsável pelos afazeres domésticos e a criação dos filhos. Ademais, com a vida predominantemente rural, os membros da família representavam força de trabalho, havendo então amplo incentivo à procriação.

A Revolução Industrial foi o principal marco para a ruptura desse perfil, devido às diversas transformações sociais que ocorreram e assim, a estrutura familiar também foi alterada. A remota concepção de composição familiar como descrita anteriormente sofreu reformulações em vista das novas necessidades do corpo social.

Nessas circunstâncias, além do advento das I e II Guerra Mundial quando os homens se ausentaram do meio laboral para ir às batalhas, deuse a introdução das mulheres no mercado de trabalho e assim, os afazeres do lar que eram imputados a elas ficaram em segundo plano. Houve a migração da família para os centros urbanos em busca de novas e melhores condições de vida e, passando a conviver em espaços menores e de custo elevado, começou-se a reconsiderar o tamanho da prole.

Nesse mesmo diapasão, Maria Berenice Dias esclarece que:

A estrutura da família se alterou. Tornou-se nuclear, restrita ao casal e a sua prole. Acabou a prevalência do seu caráter produtivo e reprodutivo. A família migrou do campo para as cidades e passou a conviver em espaços menores. Isso levou à aproximação dos seus membros, sendo mais prestigiado o vínculo afetivo que envolve seus integrantes. Surge a concepção da família formada por laços afetivos de carinho, de amor. A valorização do afeto deixou de se limitar apenas ao momento de celebração do matrimônio, devendo perdurar por toda a relação. Disso resulta que, cessado o afeto, está ruída a base de sustentação da família, e a dissolução do vínculo do casamento é o único modo de garantir a dignidade da pessoa. ${ }^{3}$

A família, portanto, não é mais condicionada aos remotos paradigmas de casamento e procriação. A emancipação feminina, em virtude dos diversos movimentos feministas, associada à disseminação dos métodos contraceptivos e à reprodução assistida, possibilitou à mulher a escolha pelo desenvolvimento profissional e planejamento da maternidade. Os casamentos arranjados não mais compõem a realidade ocidental e as

\footnotetext{
${ }^{3}$ DIAS, Maria Berenice. Manual de direito das famílias. 11. ed. São Paulo: Revista dos Tribunais, 2016, p. 48.
} 
famílias se sustentam pelos pilares dos laços afetivos, que, uma vez cessados, podem ser formalmente dissolvidos cessando o vínculo conjugal.

Nesse contexto, o conceito de família, que antes era dado apenas à tradicional, como a mulher e o homem unidos pelo matrimônio com o dever de gerar filhos, foi superado, e atualmente, despontam novos modelos familiares, mais igualitários nas relações de sexo e idade, mais flexíveis em suas temporalidades e em seus componentes, menos sujeitas à regra e mais ao desejo ${ }^{4}$.

A Constituição de 1988 reconhece a existência de outras entidades familiares além das concebidas pelo casamento sendo, a título de exemplo, a união estável no artigo 226 , parágrafo $3^{\circ}$ e a família monoparental, no artigo 226, parágrafo $4^{\circ}$, que se trata da comunidade formada por qualquer dos pais e descendentes. Ademais disso, conjunturas antes marginalizadas, como as uniões homoafetivas e o reconhecimento de filhos havidos fora do matrimônio, agora compõem o âmbito jurídico das famílias, demonstrando assim a busca do Direito em estar em conformidade com a realidade social.

O distanciamento entre a Igreja e o Estado acarretou em profundo progresso social, e dessa forma, novas estruturas de convívio começaram a surgir. A lei, no entanto, nunca buscou de fato conceituar a família, mas apenas identificava esta pelo vínculo do matrimônio, sendo negligente com os vínculos afetivos que não possuíam a formalidade estatal, inclusive negando direitos. Nesse mesmo sentido, Maria Berenice Dias:

É necessário ter uma visão pluralista da família, que abrigue os mais diversos arranjos familiares, devendo-se buscar o elemento que permite enlaçar no conceito de entidade familiar todos os relacionamentos que têm origem em um elo de afetividade, independentemente de sua conformação. Esse referencial só pode ser identificado no vínculo que une seus integrantes. É o envolvimento emocional que leva a subtrair um relacionamento do âmbito do direito obrigacional- cujo núcleo é a vontade - para inseri-lo no direito das famílias, que tem como elemento estruturante o sentimento do amor que funde as almas e confunde patrimônios, gera responsabilidades e comprometimentos mútuos. Esse é o divisor entre o direito obrigacional e o familiar: os negócios têm por substrato exclusivamente a vontade, enquanto o traço diferenciador do direito da família é o afeto. ${ }^{5}$

\footnotetext{
${ }^{4}$ DIAS, Maria Berenice. Manual de direito das famílias. 11. ed. São Paulo: Revista dos Tribunais, 2016, p. 228.

${ }^{5}$ DIAS, Maria Berenice. Manual de direito das famílias. 11. ed. São Paulo: Revista dos Tribunais, 2016, p. 231.
} 
Pelo exposto, conclui-se que após a decadência da família patriarcal, o que de fato elege uma família é a união dos elos de amor e afeto que, como bem comparado pela autora, distancia-se do direito obrigacional, em que basta a exteriorização da vontade para a realização do negócio. Da mesma forma, o afeto como o componente primordial para a família, o conceito desta tem adquirido tamanha elasticidade de maneira a já ser denominada pela doutrina de família multiespécie aquela composta pelos indivíduos e seus animais de estimação ${ }^{6}$.

Dessa forma, a escolha da constituição familiar é livre e qualquer forma de vínculo afetivo é válida, contribuindo, inclusive, para o crescimento e formação social, cabendo ao Estado, a obrigação para com o devido reconhecimento e proteção de todas as formas de família.

\section{DA JUDICIALIZAÇÃO DAS QUESTÕES FAMILIARES E SEUS IMPACTOS PERANTE OS ANIMAIS DOMÉSTICOS}

Inicialmente, no que tange à dissolução das relações afetivas, consigna-se que o Estado sempre tentou impedir a dissolução dos vínculos conjugais, de forma que não previa a possibilidade da separação se um dos cônjuges não conseguisse provar um dos motivos elencados em lei para que ocorresse tal situação, caracterizando uma postura punitiva por parte do Estado e a intenção de manter, a qualquer custo, o laço matrimonial. ${ }^{7}$

Todavia, com o advento da possibilidade do divórcio e da dissolução da união estável com a simples cessação da vida em comum, a realidade social foi de fato reconhecida pelo Direito, observando-se que as pessoas são feitas de afetos, desafetos e que o amor nasce, morre e renasce com outro parceiro.

Ao atrelar os animais de estimação à essa nova realidade, não menos importante é a presença desses nesse cenário. Assim, sob a ótica puramente normativa, o artigo 82 do Código Civil dispõe que os animais são bens considerados de natureza mobiliária:

\footnotetext{
${ }^{6}$ CHAVES, Marianna. Disputa de guarda de animais de companhia em sede de divórcio e dissolução de união estável: reconhecimento da família multiespécie?. 2015. Disponível em: $<$ https://jus.com.br/artigos/41414/disputa-de-guarda-de-animais-de-companhia-em-sede-de-divorcioe-dissolucao-de-uniao-estavel>. Acesso em: 10fev. 2018.

${ }^{7}$ DIAS, Maria Berenice. Manual de direito das famílias. 11. ed. São Paulo: Revista dos Tribunais, 2016, p. 149.
} 
Art. 82. São móveis os bens suscetíveis de movimento próprio, ou de remoção por força alheia, sem alteração da substância ou da destinação econômico-social. ${ }^{8}$

Nesse diapasão, constata-se que a regulamentação aplicável aos animais é a mesma que ampara os bens patrimoniais e, portanto, aqueles são também considerados meros objetos e possíveis de atribuição valorativa frente à legislação pátria.

As demandas jurídicas de família atualmente demonstram, no entanto, que apesar da atribuição exclusivamente econômica da legislação pátria aos animais, tem sido recorrente a busca pelo Judiciário a fim de decidir sobre o animal de companhia e a legitimidade para sua custódia quando não há consenso pelo casal sobre essa situação em sede de divórcio ou dissolução de união estável.

Desse ponto, é necessário apontar a estimativa no número de cães e gatos nos domicílios brasileiros, conforme a Pesquisa Nacional de Saúde (PNS) realizada em 2013 pelo Instituto Brasileiro de Geografia e Estatística (IBGE) em convênio com o Ministério da Saúde, a fim de demonstrar a relevância deste estudo.

Em 44,3\% das residências havia pelo menos um cachorro, o equivalente a 28,9 milhões de unidades residenciais, sendo que a população de cachorros em domicílios brasileiros foi estimada em 52,2 milhões, o que indicou uma média de 1,8 cachorro por domicílio com esse animal. Já a população de gatos em residências brasileiras foi estimada em 22,1 milhões, o que representa aproximadamente 1,9 gato por domicílio, sendo 11,5 milhões de unidades domiciliares com esse animal, o que equivale a $17,7 \%$ de domicílios. ${ }^{9}$

Neste sentido, constata-se que o número de cães nos domicílios brasileiros supera o de crianças de zero a catorze anos, que soma a quantia de 44,9 milhões, conforme a Pesquisa Nacional por Amostra de Domicílio (PNAD) realizada também em $2013^{10} \mathrm{e}$, portanto, essa realidade não pode ser menosprezada pelo Direito, juntamente com a questão abordada acerca

\footnotetext{
${ }^{8}$ BRASIL. Lei 10.406, de 10 de janeiro de 2002. Novo Código Civil Brasileiro. Diário Oficial da União, Brasília, DF, 10 jan 2002. Disponível em: <http://www.planalto.gov.br/ccivil_03/leis/2002/L10406.htm>. Acesso em: maio 2018.

${ }^{9}$ Pesquisa nacional de saúde: 2013: acesso e utilização dos serviços de saúde, acidentes e violências: Brasil, grandes regiões e unidades da federação / IBGE, Coordenação de Trabalho e Rendimento. Rio de Janeiro : IBGE, 2015.

${ }^{10}$ Pesquisa nacional por amostra de domicílios: síntese de indicadores2013 / IBGE, Coordenação de Trabalho e Rendimento. - 2. ed. - Rio de Janeiro : IBGE, 2015.
} 
da mudança de paradigma das famílias brasileiras apontada no primeiro capítulo do presente estudo.

Outra questão a ser levantada é a competência da Vara de Família ou da Vara Cível para a discussão acerca da guarda compartilhada de animais de estimação. Se apenas o rigor da lei for levado em consideração, o status jurídico dos animais de bens semoventes leva a crer que a Vara Cível seria a competente para decidir sobre os casos que envolvem a custódia de animais de estimação. No entanto, em recente julgamento de agravo de instrumento, a $7^{a}$ Câmara de Direito Privado do Tribunal de Justiça de São Paulo (TJ/SP) decidiu que a vara de Família é competente para a discussão acerca da guarda compartilhada de animais de estimação, enquanto o juiz singular teria entendido se tratar de questão cível e a não competência da Vara de Família e Sucessões.

$\mathrm{Na}$ decisão, o desembargador José Rubens Queiroz Gomes, relator do agravo, citou a jurisprudência da Corte sobre o tema, apontando a lacuna legislativa existente acerca da relação de afeto entre as pessoas e os animais, não sendo sempre a função destes a de gerar riqueza patrimonial, devendo o juiz decidir em conformidade com os preceitos estabelecidos no artigo $4^{\circ}$ da Lei de Introdução às Normas do Direito Brasileiro da analogia, dos costumes e dos princípios gerais de direito ${ }^{11}$.

\subsection{O ATIVISMO JUDICIAL E SEU REFLEXO NAS DEMANDAS DE FAMÍLIA}

O ativismo judicial, segundo Luís Roberto Barroso, entende-se como sendo o papel criativo dos tribunais ao trazerem uma nova contribuição para o Direito, expandindo o sentido e o alcance da norma constitucional através da escolha de uma interpretação específica e proativa da mesma em um caso "sub judice". Este cenário, não raras vezes, é instalado a partir da retração do Poder Legislativo, ocorrendo uma antecipação da formulação da própria lei. "A ideia de ativismo judicial está associada a uma participação mais ampla e intensa do Judiciário na

\footnotetext{
${ }^{11}$ MIGALHAS. Vara de Família tem competência para decidir guarda compartilhada de animais. 2018. Disponível em: <http://www.migalhas.com.br/Quentes/17,MI280031,101048Vara+de+Familia+tem+competencia+para+decidir+guarda+compartilhada+de $>$. Acesso em: 14 maio 2018.
} 
concretização dos valores e fins constitucionais, com maior interferência no espaço de atuação dos outros dois Poderes." 12

Em tese, todas as situações fáticas deveriam ser englobadas pelo Direito. Contudo, é sabido que ocorre um descompasso e a realidade sempre antecede o direito, pois a necessidade de tornar jurídicos atos e fatos decorre do modo reiterado de agir dos indivíduos. Aludindo mais uma vez Rodrigo da Cunha Pereira, ainda que a lei tente prever todas as situações que são dignas de tutela, as relações sociais são muito mais ricas e amplas do que é possível conter uma legislação ${ }^{13}$.

Posto isso, cabe então ao juiz suprir a lacuna legislativa, uma vez que o magistrado não pode negar proteção ou deixar de assegurar direitos sob a alegação de ausência de lei.

Assim, a aplicação do instituto da guarda compartilhada dos filhos, advindo do Direito de Família, tem sido uma das soluções plausíveis que os juízes encontraram para solucionar os casos que envolvem animais de companhia, o que demonstra uma postura ativa do Judiciário. Contudo, face à falta de regulamentação específica, a aplicabilidade ou não desse instituto fica ao mero entendimento do magistrado que pode ou não considerar razoável tal aplicação e, assim, ainda não há também uma uniformização do posicionamento da Justiça brasileira sobre esse assunto.

É inegável que a guarda de animais de estimação se trata de uma realidade da pós-modernidade e que merece tutela jurisdicional, não devendo ser olhado, até mesmo pelo próprio corpo social, como uma questão banal, pois aqui se discute relações afetivas.

\section{ALTERAÇÃO LEGAL NA NATUREZA JURÍDICA DOS ANIMAIS}

Demonstrada a realidade do tecido social como um todo, e especificamente das famílias brasileiras contemporâneas e o papel dos animais de estimação nesse seio, deve-se ainda discorrer acerca da natureza jurídica dos animais não humanos e a evolução histórica dos direitos dos animais.

12 BARROSO, Luís Roberto.Judicialização, Ativismo Judicial e Legitimidade Democrática, p.03.Disponívelem:<https://www.direitofranca.br/direitonovo/FKCEimagens/file/ArtigoBarroso_para _Selecao.pdf $>$. Acesso em: 17 maio 2018.

${ }_{13}$ PEREIRA, Rodrigo da Cunha. Princípios fundamentais e norteadores para a organização jurídica da família. 2. ed. Belo Horizonte: Del Rey, 2012. 
Para tanto, o professor Flávio Martins entende, juntamente com parte da doutrina, existirem direitos de quinta dimensão, os quais são "os direitos de dever, cuidado, respeito quanto a outras formas de vida, além da humana" 14 .

Assim, juntamente com a abordagem do referido professor, no decorrer deste artigo, pode-se notar que a definição de res aos animais não humanos não mais se sustenta no ordenamento jurídico brasileiro, principalmente ante a demonstração nos tópicos anteriores da existência de vínculo afetivo entre os animais de estimação e seus donos, e a busca por estes pelo Judiciário a fim de que tal relação seja reconhecida em face das dissoluções amorosas.

Há ainda muito a percorrer nas conquistas dos direitos dos animais, principalmente devido ao antropocentrismo enraizado na sociedade, de forma que, brilhantemente, o civilista Nelson Rosenvald aponta que ainda não há um preparo do corpo social em considerar os animais como titulares de direito, entretanto, deve-se pouco a pouco caminhar para essa consideração, iniciando-se através do afastamento da referida visão antropocêntrica:

Que ainda prevaleça uma visão antropocêntrica, porém menos
exacerbada e em conformação com uma perspectiva
intergeracional, pois os nossos filhos e netos não merecem viver
em um planeta no qual o ser humano caminha a passos largos para
se tornar a espécie única. ${ }^{15}$

Nesse ínterim, fica demonstrado que cabe ao tecido social desvincular-se dos grilhões da obsoleta pregação do especicismo, que coloca a espécie humana como superior às outras espécies de animais, ao ponto destas deverem unicamente servir aos humanos; somente a partir desse avanço social poderá vir como consequência uma mudança no ordenamento jurídico brasileiro e, assim, uma definição mais justa e compatível com a atual demanda judiciária em relação à guarda de animais de companhia.

\footnotetext{
${ }^{14}$ NUNES JÚNIOR, Flávio Martins Alves. Curso de direito constitucional. 2. ed. São Paulo: Revista dos Tribunais, 2018, p. 792.

15 NELSON ROSENVALD apud NUNES JÚNIOR, Flávio Martins Alves. Curso de direito constitucional. 2. ed. São Paulo: Revista dos Tribunais, 2018, p. 819.
} 


\section{5}

\section{O INSTITUTO DA GUARDA COMPARTILHADA PERANTE OS ANIMAIS DE ESTIMAÇÃO E LEGISLAÇÃO ESPECIAL}

Certamente não é o objetivo atribuir aos animais de companhia as mesmas características e/ou responsabilidades, sejam elas jurídicas ou não, a que se incumbe aos pais perante os filhos. De toda forma, não restam dúvidas de que a disputa pela guarda desses animais se deve a uma realidade pós-moderna, que atribui a eles a existência de aspectos não patrimoniais, face às mudanças no seio familiar.

À vista disso, não se olvida que a Constituição Federal de 1988 introduziu o princípio da pluralidade das formas de família, mesmo que implicitamente, ao permitir que as estruturas familiares adquiram novas molduras.

Com caráter vanguardista, o reconhecimento da família multiespécie, como já definida alhures, por aquela composta pelas pessoas e seus animais de estimação, trata-se de mais uma nova entidade familiar composta por um elo de afetividade, de maneira que excluí-la do âmbito da juridicidade, nas palavras de Maria Berenice Dias, "é afrontar a ética, é ser conveniente com a injustiça". ${ }^{16}$

Nesse sentido, a guarda de animais de estimação não pode ser tratada como um tema banal ou inócuo, ao revés, o referido assunto pode abrir margem para inúmeras implicações graves e injustiças.

Assim, a aplicação do instituto da guarda compartilhada do Direito de Família, referente aos filhos menores mostra-se, atualmente, a medida mais plausível a ser empregada pelos magistrados quando o casal recém-separado não acorda sobre a guarda do animal.

Nada impede também que uma espécie de "pensão" seja fixada, haja vista que o animal demanda custos, como alimentação, higiene e vacinação. Essa possibilidade de suporte financeiro já possui diversos precedentes na jurisprudência norte-americana, sendo inclusive denominado "petimony", aludindo à terminologia "alimony" que é utilizada para pensão de alimentos na língua inglesa. Em um caso concreto americano, além das partes acordarem em partilhar a custódia do animal de

\footnotetext{
${ }^{16}$ DIAS, Maria Berenice. Manual de direito das famílias. 11. ed. São Paulo: Revista dos Tribunais, 2016, p. 80.
} 
companhia, o ex-marido foi compelido a pagar uma pensão mensal de 150 dólares para cobrir os gastos com o animal. ${ }^{17}$

Portanto, não podendo o Direito se omitir frente às novas realidades que lhe são impostas de tempos em tempos, a aplicação do instituto da guarda compartilhada para os animais de estimação não se mostra tão distante de uma solução jurídica-social que aqueles que buscam o Judiciário a fim de garantir o convívio com o animal, mesmo após a dissolução amorosa entre o casal.

Nada obstante se tratar de uma "boa saída" a aplicação do referido instituto, não se olvida que aos animais de estimação algumas questões não são a eles aplicáveis, como o são para os filhos menores. Nesse mesmo diapasão, Marianna Chaves expõe:

\footnotetext{
Ainda que situações relativas à custódia de animais de companhia e guarda de crianças e adolescentes possam ser muito similares em alguns aspectos, as disputas relativas a animais são inerentemente diferentes. Destarte, é imperiosa a criação de um estatuto jurídico próprio, que atenda especificamente a essas demandas e seja adequado às singularidades da relação entre humanos e pets. ${ }^{18}$
}

Assim, a elaboração de uma legislação específica faz-se necessária, para que de fato os interesses dos animais de estimação e também de seus donos possam ser atendidos. Com uma regulamentação específica, se poderia evitar uma discussão mais longa e demorada no judiciário acerca dessa questão da custódia do animal, evitando-se também como consequência, a judicialização dessa questão apenas a fim de causar maiores intrigas e desgaste para o ex-companheiro.

\section{CONSIDERAÇÕES FINAIS}

O tema exposto nesse artigo teve a intenção de demonstrar a realidade pós-moderna no tocante às novas modalidades de famílias, e a situação dos animais de estimação quando da fragmentação do

${ }^{17}$ CHAVES, Marianna. Disputa de guarda de animais de companhia em sede de divórcio e dissolução de união estável: reconhecimento da família multiespécie?. 2015. Disponível em: $<$ https://jus.com.br/artigos/41414/disputa-de-guarda-de-animais-de-companhia-em-sede-de-divorcioe-dissolucao-de-uniao-estavel>. Acesso em: 08 ago. 2018.

${ }^{18}$ CHAVES, Marianna. Disputa de guarda de animais de companhia em sede de divórcio e dissolução de união estável: reconhecimento da família multiespécie?. 2015. Disponível em: $<$ https://jus.com.br/artigos/41414/disputa-de-guarda-de-animais-de-companhia-em-sede-de-divorcioe-dissolucao-de-uniao-estavel>. Acesso em: 10 ago. 2018. 
relacionamento afetivo de seus donos. Pode-se verificar que o tema se trata de situação mais abrangente do que pode parecer a princípio.

Assim, foi constatado que os animais de estimação estão cada vez mais inseridos nas famílias e criam laços de afeto com seus donos, de maneira que questões como o divórcio ou a dissolução da união estável também os atingem e a legislação pátria, ao considerá-los bens semoventes, não consegue solucionar os casos cada vez mais recorrentes de pedido de guarda compartilhada ou direito de visita aos animais de estimação.

Ao analisar a interferência do judiciário e a postura mais ativa do magistrado, principalmente no tocante à inexistência de regulamentação específica para o tema da presente pesquisa, averiguou-se que as questões inerentes ao Poder Legislativo, não raro, são passadas aos juízes, uma vez que eles não podem deixar de apreciar as questões que lhes são submetidas e, da mesma forma, não pode o jurisdicionado ficar à espera de elaboração legislativa para pleitear seus direitos que merecem a chancela estatal.

A necessidade do reconhecimento e atribuição aos animais a uma terceira linhagem que não os consideram nem coisa inanimada e nem humano, além do reconhecimento da família multiespécie, mostraram-se de suma importância para que, a partir de então possa haver a elaboração de uma legislação especial para os casos de custódia do animal quando da dissolução conjugal ou convivencial.

A passagem de uma das obras do filósofo Voltaire, que foi um dos primeiros intelectuais a refletir de forma diversa quanto aos animais não humanos, demonstra a existência de sensibilidade no animal e ignorála seria o mesmo que ir contra a natureza do ser:

Que ingenuidade, que pobreza de espírito, dizer que os irracionais
são máquinas privadas de conhecimento e sentimento, que
procedem sempre da mesma maneira, que nada aprendem, nada
aperfeiçoam! (...) Vês-me entrar em casa aflito, procurar um papel
com inquietude, abrir a escrivaninha, onde me lembra tê-lo
guardado, encontrá-lo, lê-lo com alegria. Percebes que
experimentei os sentimentos de aflição e prazer, que tenho
memória e conhecimento. Vê com os mesmos olhos esse cão que
perdeu o amo e procura-o por toda parte com ganidos dolorosos,
entra em casa agitado, inquieto, desce e sobe e vai de aposento em
aposento e enfim encontra no gabinete o ente amado, a quem
manifesta sua alegria pela ternura dos ladridos, com saltos e
carícias. Bárbaros agarram esse cão, que tão prodigiosamente
vence o homem em amizade, pregam-no em cima de uma mesa e
dissecam-no vivo para mostrar-te suas veias mesaraicas ${ }^{19}$.

${ }^{19}$ Veias que vêm do reto e do intestino Delgado e chegam à cabeça de pâncreas e contribuem para formar a veia porta. 
Descobres nele todos os mesmos órgãos de sentimento de que te gabas. Responde, maquinista, teria a natureza entrosado nesse animal todos os elatérios do sentimento sem objetivo algum? Terá nervos para ser insensível? Não inquines à natureza tão impertinente contradição. ${ }^{20}$

A presente pesquisa constatou que o vínculo entre o ser humano e um animal, cada vez mais, ultrapassam os valores patrimoniais que aos animais podem ser atribuídos, de maneira que os animais de estimação passaram a ser parte integrante da família e merecem, junto a seus donos, a tutela jurisdicional para as questões que pretendem nada mais que garantir a manutenção de um vínculo afetivo construído entre eles.

Deve o Estado, portanto, garantir a nova modalidade familiar pós-moderna que inclui os animais de companhia em seu âmago e, principalmente, de maneira coerente e específica as questões relativas aos casos de disputa da guarda de animais de estimação quando da dissolução amorosa de seus donos. Insta mencionar ainda que para Maria Berenice Dias, "o afeto merece ser visto como uma realidade digna de tutela" e, destarte, o amor por um animal não difere do amor entre as pessoas, nem pode ser prejudicado quando da dissolução dos relacionamentos.

\section{REFERÊNCIAS BIBLIOGRÁFICAS}

BARROSO, Luís Roberto. Judicialização, Ativismo Judicial e Legitimidade Democrática, p.03. Disponível em:

<https://www.direitofranca.br/direitonovo/FKCEimagens/file/ArtigoBarroso_para_Selecao.pdf>. Acesso em: 17 maio 2018.

BRASIL. Lei 10.406, de 10 de janeiro de 2002. Novo Código Civil Brasileiro. Diário Oficial da União, Brasília, DF, 10 jan 2002. Disponível em:

<http://www.planalto.gov.br/ccivil_03/leis/2002/L10406.htm>. Acesso em: maio 2018.

CHAVES, Marianna. Disputa de guarda de animais de companhia em sede de divórcio e dissolução de união estável: reconhecimento da família multiespécie?. 2015. Disponível em:

$<$ https://jus.com.br/artigos/41414/disputa-de-guarda-de-animais-de-companhia-em-sede-de-divorcioe-dissolucao-de-uniao-estavel>. Acesso em: 10fev. 2018.

DIAS, Maria Berenice. Manual de direito das famílias. 11. ed. São Paulo: Revista dos Tribunais, 2016.

\footnotetext{
${ }^{20}$ VOLTEIRE, Dicionário filosófico, p.127 apud NUNES JÚNIOR, Flávio Martins Alves. Curso de direito constitucional. 2. ed. São Paulo: Revista dos Tribunais, 2018, p. 807-808.
} 
MIGALHAS. Vara de Família tem competência para decidir guarda compartilhada de animais. 2018. Disponível em: <http://www.migalhas.com.br/Quentes/17,MI280031,101048-

Vara+de+Familia+tem+competencia+para+decidir+guarda+compartilhada+de $>$. Acesso em: 14 maio 2018.

NELSON ROSENVALD apud NUNES JÚNIOR, Flávio Martins Alves. Curso de direito constitucional. 2. ed. São Paulo: Revista dos Tribunais, 2018.

NUNES JÚNIOR, Flávio Martins Alves. Curso de direito constitucional. 2. ed. São Paulo: Revista dos Tribunais, 2018.

PEREIRA, Rodrigo da Cunha. Princípios fundamentais e norteadores para a organização jurídica da família. 2. ed. Belo Horizonte: Del Rey, 2012.

Pesquisa nacional de saúde: 2013: acesso e utilização dos serviços de saúde, acidentes e violências: Brasil, grandes regiões e unidades da federação / IBGE, Coordenação de Trabalho e Rendimento. Rio de Janeiro: IBGE, 2015.

Pesquisa nacional por amostra de domicílios: síntese de indicadores2013 / IBGE, Coordenação de Trabalho e Rendimento. - 2. ed. - Rio de Janeiro : IBGE, 2015.

VOLTEIRE, Dicionário filosófico, p.127 apud NUNES JÚNIOR, Flávio Martins Alves. Curso de direito constitucional. 2. ed. São Paulo: Revista dos Tribunais, 2018. 